\title{
Motivation and the behavioral effects of LSD'
}

\section{J. B. APPEL. W. E. WHITEHEAD, and D. X. FRLEIMAN, The} University of Chicago, Chicago, Ill. 606.37

The acute behavioral effects of LSD were measured in 2.3 rats trained to press a bar on a fixed-ratio schedule of food rcinforcement. At any level of deprivation, rate of responding is a decreasing monotonic function of doses of $0.02-0.20 \mathrm{mg} \mathrm{LSD} / \mathrm{kg}$. Increasing hunger generally decreases amount of effect.

Lysergic acid diethylamide (LSD) and pharmacologically similar but less potent compounds which are psychedelic, hallucinogenic or psvchotomimetic in man have effects on animal behavior which differ in important ways from those of other kinds of psychoactive agents (Appel, 1967). For example, in contrast to tranquilizers such as chlorpromazine, LSD tends to disrupt sustained patterns of positively reinforced responding such as working for food on a fixed-ratio (FR) schedule more than it interferes with behavior involving shock escape or avoidance (Barry et al, 1963; Ray, 1965; Appel et al, 1967). Such differences in the behavioral effects of different kinds of drugs could of course be the result of (1) different relationships between stimulus, response, and reinforcement variables which are usually programmed in different situations involving the two modalities of stimulation, i.e., food vs shock (Dews \& Morse, 1961), (2) differential drug effects on sensitivity to the modality of stimulation, or (3) motivatonal variables. Because there is evidence that both desire to eat (Hamilton \& Wilpizeski, 1961) and motivation-related processes like attention, habituation, and arousal (Bradley \& Key, 1958) are greatly affected by LSD, the present experiment was run to evaluate the effects of one kind of motivation, degree of hunger, over a wide range of doses without confounding the variable with other determinants of drug response.

\section{Subjects}

\section{METHOD}

The Ss were 23 male albino rats of Sprague-Dawley strain obtained from the Charles River Breeding Laboratories, Wilmington, Mass. They were experimentally naive and 90 days old at the beginning of the investigation.

Apparatus

The animals were housed in individual home cages in a climate controlled room kept at $75 \mathrm{deg} F$ on a 12-h day-night cycle (7:00 AM-7:00 PM). They were run in two experimental chambers which have been described in detail elsewhere (Freedman et al, 1964). The boxes contained a single lever, a dim house light directly above the lever, and a dipper feeder which delivered 0.05 $\mathrm{ml}$ of a diet of sweetened milk and vitamins when programmed to do so. Each box was enclosed in a separate light and sound attenuating shell. All experimental events were programmed by switching and timing circuits in an adjoining room. Bar-pressing responses were recorded on electromagnetic counters and cumulative recorders.

Behavioral Procedure

The Ss were divided into three groups of 8,7 , and 8 animals. In a $100 \%$ or least hungry group, the body weight of each S was kept at the weight it attained during the last of 10 days of free-feeding by feeding appropriate amounts of Purina Laboratory Chow. In an intermediately hungry $(90 \%)$ group, weights were maintained at $90 \%$ of free-feeding weight and in the most hungry group, body weights were allowed to fall to $80 \%$ of normal. In practice, the three groups differed throughout the experiment both in terms of average body weight and amount of supplementary food the Ss received; this turned out to be about $15 \mathrm{~g}$ per day in the $100 \%$ groups, $10 \mathrm{~g}$ in the $90 \%$ group and $5 \mathrm{~g}$ in the $80 \%$ group.

The Ss were trained to press the bar for milk in the presence of the house light. They were run for a period of several months at the same time of day every other day during which the ratio of responses required for reinforcement was gradually raised such that all Ss had to respond on an FR 40 schedule. They were then run for a period of about three weeks in which rates of bar-pressing were allowed to stabilize. The rate during the last five pre-drug sessions was taken as each $S$ 's base line rate; this rate did not change systematically during subsequent non-drug sessions.

Pharmacological Procedure

Each $\mathrm{S}$ was given an injection of $0.3 \mathrm{ml}$ of isotonic saline solution intra-peritoneally (i.p.) prior to each non-drug session from the time it reached FR 40 until the end of the experiment. LSD was administered from ampuls of $0.1 \mathrm{mg} / \mathrm{ml}$ obtained from the National Institute of Mental Health and prepared originally by Sandoz Pharmaceuticals, Hanover, New Jersey. The drug was always given in an ascending order of doses $(0.02,0.04,0.06$, $0.08,0.10,0.12,0.14,0.16,0.18,0.20 \mathrm{mg} / \mathrm{kg}$ ). Each drug day was separated from the preceding drug day by at least one week (three to four experimental days) to control for tolerance to the behavioral effects of the drug (Freedman et al, 1964); in addition, LSD was never given until each S's rate attained its base line level under control (i.e., saline) conditions.

RESULTS

The acute effects of LSD, i.e., those which occur during the first hour after i.p. injection, on bar-pressing behavior maintained by FR reinforcement have been described in detail elsewhere (Freedman et al, 1964), but quantitative data for a wide range of doses are presented for the first time in Fig. 1 which shows average rates of bar-pressing at each dose expressed as a per cent of base line FR rate (above). Rate is a decreasing monotonic and probably exponential function of dose.

The disruption in overall rate shown in the figure results primarily from the occurrence of one or more drug-induced periods of pausing or no responding which usually begin $4-8 \mathrm{~min}$ after (i.p.) injection and may, but need not necessarily, occur after reinforcement. Changes in local response rates are otherwise rare but when they do occur they immediately precede or immediately follow the period (s) of pausing.

Increasing motivation (by decreasing body weight) generally attenuates the effect of LSD at doses above $0.04 \mathrm{mg} / \mathrm{kg}$ by decreasing the duration of pausing. This is reflected in the figure by a displacement of the dose-response curve in the most hungry group to the right. In contrast to the least hungry group, effects

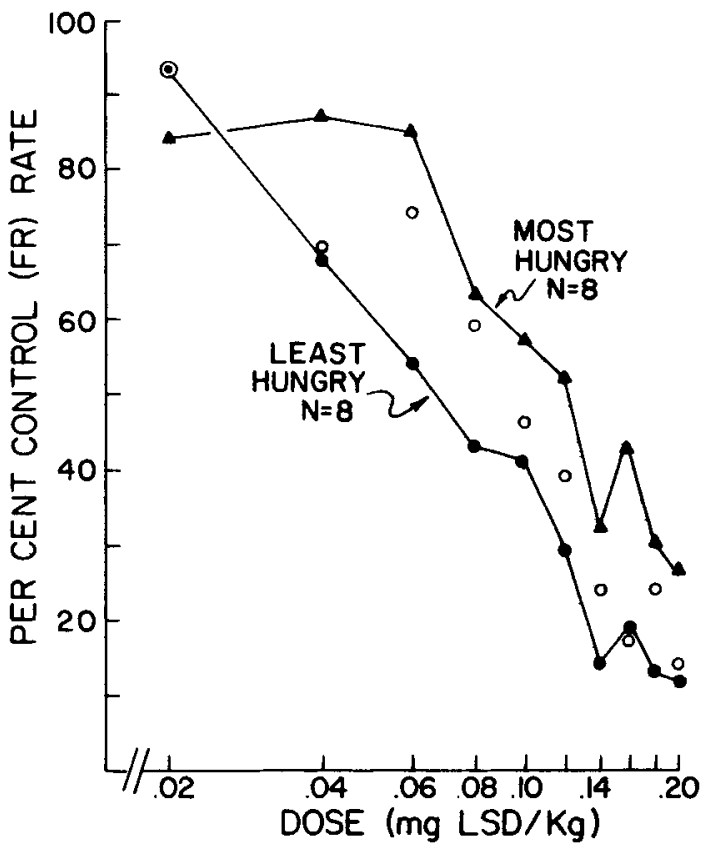

Fig. 1. 
do not begin in very hungry animals until $0.80 \mathrm{mg} \mathrm{LSD} / \mathrm{kg}$ is given.

While the rank order of effects at all doses (except $0.16 \mathrm{mg} / \mathrm{kg}$ ) parallels amount of deprivation, the intermediately (90\%) hungry group (shown by un-joined circles) did not differ significantly from either the most or least hungry groups in any consistent manner (t-tests between the $90 \%$ and $80 \%$ groups were significant at $0.04,0.16$ and $0.20 \mathrm{mg} \mathrm{LSD} / \mathrm{kg}$ at the 0.05 level of confidence but none of the t-tests between the $90 \%$ and $100 \%$ groups were significant beyond the 0.10 level). Comparisons of the performances of the most and least hungry groups revealed, however, that not only were the overall curves different (the average per cent of base line rate pooled over doses was $\mathbf{3 8}$ for the least hungry, and 59 for the most hungry group) but t-values generally increased as dose increased (and variance decreased) such that at $0.06,0.08,0.10$, and $0.12 \mathrm{mg} \mathrm{LSD} / \mathrm{kg}, 0.05<\mathrm{p}<.10$ and at $0.14,0.16,0.18$, and $0.20 \mathrm{mg} \mathrm{LSD} / \mathrm{kg}, \mathrm{t}$ was significant $(p<.05$ in each case) .

\section{DISCUSSION}

While the deprivation technique used in this experiment may not be ideal (the $90 \%$ group did not differ in a consistent manner from either of the other groups), the results clearly indicate that increasing hunger attenuates the effects of LSD. At low doses $(0.04$ and $0.06 \mathrm{mg} / \mathrm{kg})$, LSD has virtually no effect in hungry animals; at higher doses $(0.14-0.2 \mathrm{mg} / \mathrm{kg})$, it has significantly smaller effects. It would thus appear that the behavioral response(s) to relatively potent compounds (Appel \& Freedman, 1965) can be at least partially attenuated by increasing the motivation of the $S$ to work for whatever reinforcement it would obtain if the drug were not effective. The clinical as well as methodological implications of such a finding are obvious.

\section{REFERENCES}

APPEL, J. B. The behavioral pharmacology of LSD-Animal Studies. Paper read at American College of Neuropsychopharmacology. San Juan, Puerto Rico, 1967.

APPEL, J. B., \& FREEDMAN, D. X. The relative potencies of psychotomimetic drugs. Life Sciences, 1965, 4, 2181-2186.

APPEL, J. B., FREEDMAN, D. X., \& FILBY, Y. M. The effects of three psychoactive drugs on two varieties of escape behavior. Avchives Internationales de Pharmacodynamie et de Therapie. 1967, 167, 179-193.

BARRY, H., III, WAGNER, S. A., \& MILLER, N. E. Effects of several drugs on performance in an approach-avoidance conflict. Psychological Reports, $1963,12,215-221$.

BRADLEY, P. B., \& KEY, B. J. The effects of drugs on arousal responses produced by electrical stimulation of the reticular formation of the brain stem. Electroencephalography \& Clinical Neurophysiology, 1958, 10, 97-110.

DEWS, P. B., \& MORSE, W. H. Behavioral pharmacology. Annual Review of Pharmacology, 1961, 1, 145-174.

FREEDMAN, D. X., APPEL, J. B., HARTMAN, F. R., \& MOLLIVER, M. E. Tolerance to behavioral effects of LSD-25 in rat. Journal of Pharmacology \& Experimental Therapeutics, 1964, 143, 309-313.

HAMILTON, C. L., \& WILPIZESKI, C. Effects of LSD-25 on food intake in the rat. Proceedings of the Society for Experimental Biology and Medicine, 1961, 108, 319-321.

RAY, O.S. The effect of psychotogens on approach and avoidance behavior International Journal of Neuropsychiatry, 1965, 1, 98-103.

NOTE

1. This research was supported by USPHS Research Grant MH-13186, from the National Institute of Mental Health. 